\title{
How Do You Behave at the Zoo? A Look at Visitor Perceptions of Other Visitors' Behavior at the Zoo
}

\author{
Skylar L. Muller, Samantha L. Bissell ${ }^{+}$, Kristen M. Cunningham ${ }^{+}$, and Rosemary Strasser \\ Department of Psychology- Neuroscience \& Behavior, the University of Nebraska at Omaha \\ + indicates authors contributed equally to this manuscript \\ *Corresponding author (Email: rstrasser@ unomaha.edu, Orcid ID: https://orcid.org/0000-0003-4983-3057)
}

Citation - Muller, S. L., Bissell, S. L., Cunningham, K. M., \& Strasser, R. (2021). How do you behave at the zoo? A look at visitor perceptions of other visitors' behavior at the zoo. Animal Behavior and Cognition, 8(4), 619-631. https://doi.org/10.26451/abc.08.04.12.2021

\begin{abstract}
Previous research regarding behaviors of zoo visitors near exhibits has shown that they can influence animals' well-being. What is unclear is whether people's views concerning the purpose of zoos or their beliefs might influence their perception of what is acceptable behavior when visiting the zoo. In this study, we used naturalistic observation to examine zoo visitor behavior near specific exhibits. We also surveyed visitors regarding the purpose of zoos, their perception of animals and the zoo, and if they have seen inappropriate behavior in other zoo visitors. We observed visitors engaging in various inappropriate behaviors such as hitting the glass and trying to provoke the animals. These same inappropriate behaviors were also reported by visitors in our survey, indicating an awareness of what behaviors might be disruptive to animals. Visitors who reported similarities between humans and animals reported more inappropriate behaviors in others partially due to having more empathy for animals. When asked to consider the purpose of the zoo, education and conservation were ranked as being the most important, entertainment and research the least important priorities. However, of those who identified entertainment as most important, this group also reported humans to have less similarity with animals and reported less inappropriate behaviors in other visitors. Our findings suggest that zoo visitors' views regarding the purpose of zoos and perceived human similarities to animals influence what they considered inappropriate behavior around captive zoo animals. This study provides the first exploration concerning the perception of visitors regarding other visitor behaviors directed towards zoo animals.
\end{abstract}

Keywords - Zoo visitor effects, Human-animal relationships, Empathy, Conservation education, Entertainment

The interaction of visitors with zoo animals and subsequent effects on the animals' behavior, also known as the visitor effect, has been an interest of zoos because of the increasing importance of animal welfare since the 1970s (Hediger, 1970; Rose et al., 2020; Sherwen \& Hemsworth, 2019). Zoo visitors' behavior near exhibits can directly impact the behavior of the animals within the enclosures in a positive, neutral, or negative manner (Cole \& Fraser 2018; Fernandez et al., 2009; Hosey, 2013; Lewis et al., 2020; Sherwen \& Hemsworth, 2019). Although the effect of visitors can vary, the negative effects of visitor interactions are of concern for the wellbeing of zoo animals. For example, high noise levels produced by zoo visitors can cause vibrations near specific exhibits. This has been shown to produce distressing behaviors in captive animals, such as reduced foraging, decrease in exploration, and more avoidance or hiding from visitors (Brike, 2002; Kratochvil \& Schwammer, 1997; Quadros et al., 2014). Negative or disruptive behaviors from zoo visitors, such as feeding, teasing, shouting and other loud noises, as well as vandalism, can also cause distress or death to the target animals (Davey, 2007; Hediger, 1969; Thompson, 
1976). Although much of the literature has focused on the negative effects of zoo visitors especially in nonhuman primates, research into the positive interactions of zoo visitors is equally important (Sherwin \& Hemsworth, 2019). More studies using a range of species and enclosure types might lead to a better understanding and inform zoos on ways to create positive human-animal interactions at various exhibits (Sherwen \& Hemsworth, 2019). Additionally, when examining zoo visitor effects, it is very important that we also try to determine what zoo visitors understand about their behavior and its effects on animals in the enclosures. In other words, is the average zoo visitor aware that certain behaviors or interactions with animals can be physically or psychologically harmful or beneficial to the animals?

Historically, zoological parks have been a source of entertainment for the public (Carr \& Cohen, 2011). Most modern zoos, however, promote their roles in education, conservation, research, and animal welfare. Education and conservation are common themes found in the mission statement of many zoological parks (Carr \& Cohen 2011; Fernandez et al., 2009; Godinez \& Fernandez, 2019; Patrick et al. 2007; Roe et al., 2014). Globally, zoos often prioritize education which is also a priority for many zoo visitors (Roe et al., 2014). But when visitors were asked what they believe the purpose of the zoo is, the answer was usually entertainment (Carr \& Cohen 2011). Carr and Cohen (2011) suggest this is due to the historical background of zoos and how zoos present information on their website. In this study, when zoo websites were assessed, the wording along with links ('attractions', 'what to do', 'fun zoo', etc.) throughout was geared towards the idea of entertainment for visitors. This emphasis on entertainment, however, is not necessarily in conflict with animal welfare. For example, many visitors are more attracted to immersive zoos where the enclosures are more naturalistic and animals have more land to roam (Davey, 2006, 2007; Godinez \& Fernandez, 2019; Woods, 2002). When a visitor feels they have had an encounter or 'connection' with an animal, such as eye contact, they are likely to have a strong positive emotional response towards the animal (Brando \& Herrelko, 2021; Powell \& Bullock, 2014), and ratings of conservation and care have been positively associated (Howell et al., 2019). Animals that are active and engaging, for example when polar bears display animated activity, create enhanced learning opportunities and increased attendance by zoo visitors (Altman, 1998). Zoos within the last several years, therefore, have made it easier for visitors to have these engaging and immersive experiences, while at the same time promoting positive animal welfare, education, and conservation (Andersen, 2003).

Another consideration of the visitor effect is how similar the animals in an exhibit are to the visitors. Humans tend to show a preference towards animals that share similar biological or behavioral traits (Batt, 2009; Beatson \& Halloran, 2007). Specifically, people tend to find more similarities with, and have more positive emotional responses to, large vertebrates like gorillas, whereas snakes and invertebrates are generally disliked and bring forth negative emotions in zoo visitors (Batt, 2009; Myers et al., 2004). When zoo visitors were asked by researchers to rank animal species from three different exhibits (gorilla, okapi, snake) in terms of which they empathized with more, gorillas and okapi received higher empathy rankings compared to snakes (Myers et al., 2004). This preference for bio-behavioral similarity with humans, such as large charismatic megafauna, attracts visitors as well as increases monetary support for conservation efforts (Hosey et al., 2020). The challenge today for many zoos and conservation researchers is to encourage ways for the public to form that connection to lesser-known or a wider array of species (Skibins et al., 2013, 2017). Forming a connection with animals with less biobehavioral similarity might be easier for some people than for others. People with higher human-human empathy scores, for example, were also more concerned with animals' well-being (Taylor \& Signal, 2005). What is missing from much of the research in this area, is how empathy towards animals as well as other beliefs such as the purpose of a zoological park, might influence visitors' perception of an animals' wellbeing.

In the following study, we examined if visitors' beliefs about the purpose of a zoo, their perception of how similar humans are to animals, and their reported empathy for animals influenced their perception of zoo animals' well-being. Specifically, we used both naturalistic observation and a survey to determine if inappropriate visitor behaviors, such as disrupting animals by making noise, poking, or feeding animals, were observed and if zoo visitors report seeing others engaging in these behaviors. It is not uncommon for zoo staff to report seeing inappropriate visitor behaviors, but it is unknown whether 
visitors themselves recognize that certain behaviors can have a negative effect on the welfare of the animals. While previous studies have shown that zoo visitors have a more positive perception of zoo animals than the public as a whole (Reade \& Waran, 1996), it is unclear if having more positive attitudes and a positive visitor experience might influence the way visitors behave towards zoo animals (Chiew et al., 2021). It is possible that some visitors might not understand that certain behaviors might harm the animals, or they might view animals so differently from humans that they do not recognize that certain behaviors could be harmful. Another aim of this study was to determine if zoo visitors, who report more bio-behavioral similarity between humans with animals, might be more likely to notice negative visitor behavior in others.

We also investigated whether the perceived purpose of a zoo might influence zoo visitor behavior. The reason is that although the modern zoo emphasizes education and conservation in their mission statements, many studies still report that visitors view zoos as a source of entertainment (Carr \& Cohen, 2011); while others have found that conservation learning is a high priority with some zoo visitors (Ballantyne \& Packer, 2016; Roe et al., 2014). To our knowledge, no study has investigated whether visitors' perceived purpose of zoos influences their perception of animals in the exhibits or their wellbeing. We predicted that people who ranked entertainment as an important priority of a zoological park would report less similarity between humans and animals and would report less inappropriate behavior from other visitors around zoo animals. This study provides the first exploration concerning the perception of visitors regarding other visitor behaviors directed towards zoo animals.

\section{Method}

\section{Participants}

Naturalistic observations of visitors near exhibits consisted of 223 adult visitors, 76 males (34\%) and 147 women $(66 \%)$ with $64 \%$ estimated to be between the ages of $19-30$ years old and 36\% estimated to be 30 and older. Naturalistic observation consisted of observing participants near exhibits with no interference or manipulation from researchers. Following the observation, visitors were asked to participate in a zoo survey. Twenty-two individuals declined to fill out the survey leaving a total of 201 completed surveys. Informed consent was obtained from survey participants. This study was approved by the review board associated with the University of Nebraska at Omaha (protocol \#260-16-EX).

\section{Data Collection and Exhibits}

Data were collected multiple times a week during the summer of 2016 at the Henry Doorly Zoo and Aquarium in Omaha, Nebraska. Given that previous research has shown that the type of exhibit and animal can influence visitor attitudes (Pedersen et al., 2019), we collected our observations in three exhibits: an older, big cat exhibit, a modern naturalistic gorilla exhibit, and an immersive butterfly exhibit. Both the cat and gorilla exhibit have indoor housing facilities with open yards for roaming, but the gorilla exhibit is newer with much more naturalistic plants and glass fronts, rather than bars, for viewing. Enrichment is present in both indoor and outdoor enclosures. The butterfly exhibit is a modern indoor housing unit for insect species with immersive trails and free-ranging butterflies and birds within the exhibit. These exhibits were also selected to represent a range of animals in terms of their similarity to humans (butterflies being less like humans, gorillas being the most similar). We randomized the order and time of day in which exhibits were observed. Only one exhibit was observed on a given day to make sure the same zoo visitors were not observed multiple times at different exhibits within that day.

\section{Procedure}

Naturalistic observation, where the researcher observes a subject in an environment without disrupting or altering the subjects' behavior, was used to observe zoo visitors during this study. To remain discreet during observations, researchers wore casual attire, such as shorts and a t-shirt, and stood/sat away from main pathways, not obstructing the view of any exhibit. Every fourth adult who came into 
view of the researcher was chosen to be observed. Based on a pilot study done earlier, every fourth person was used because it allowed researchers enough time to write notes concerning behaviors and comments made. All inappropriate behaviors were recorded (see Table 1 for descriptions) and one-zero sampling was used for positive and negative comments concerning the animals or exhibits (see Appendix A for ethogram). Initially, two researchers conducted naturalistic observations to determine inter-rater reliability but only the data from the lead researcher (S. M.) were used in our analysis. Following the three-minute observation, only then was a visitor approached asking if they wished to complete a zoo survey. This allowed time to finish with an individual before returning to a discreet position for the next naturalistic observation. We recorded behaviors observed by visitors (e.g., reading signs) and their comments (e.g., "this enclosure is so spacious") directed towards animals or the exhibit at the request of the zoo staff. We also recorded "inappropriate" behaviors such as disruptive, or unwanted behaviors observed (e.g., hitting glass enclosure) and comments (e.g., "that animal is filthy") directed towards animals or the exhibit (See Appendix A). Only behaviors and comments of the visitor being observed were recorded irrespective of other visitors and their behaviors/comments.

Table 1

Description of Inappropriate Behaviors in Zoo Visitors

\begin{tabular}{ll}
\hline Behavior & Description \\
\hline Provoking Animals & Yelling or making noises to provoke animals \\
Feeding animals & Feeding animals human food or other matter \\
Attention Seeking & Taunting, throwing objects, poking with sticks \\
Barrier Intrusion & $\begin{array}{l}\text { Attempting to get into an exhibit, over barrier/ making contact with animals } \\
\text { in the exhibit }\end{array}$ \\
Disruptive Children & Lack of supervision of children \\
\hline
\end{tabular}

\section{Survey Collection}

After three minutes of discreet observation, the observed visitor was approached by the researcher and asked if they would like to complete a survey on zoo visitors (only adults over the age of 19 were observed and able to participate). Participants were then informed that the survey contained seven questions and lasted approximately five minutes (Appendix B). If the participant declined to take the survey, they were thanked for their time and the researcher went back to their observations. If the participant agreed to take the survey, they were handed a copy to examine while the researcher read the survey to the participant to ensure that the participant understood what was being asked in each question. The survey included questions that asked visitors to rank the most important purposes of a zoo from the list of education, conservation, entertainment, and research from 1 (most important) to 4 (least important). Participants were also asked how similar people are to animals on a Likert scale from 1 (separate, nothing in common) to 5 (close, several things in common). This was adapted from the "Inclusion of Others in Self Scale," which includes a singular item illustrated rating of closeness (Aron et al., 1992). They were also asked if zoo animals were influenced by visitor behavior, if they identified and empathized with zoo animals, if they attended zookeeper demonstrations, and viewed signs to learn more about animals using a Likert scale from 1 (disagree) to 5 (agree). They were also asked to indicate if they had personally seen inappropriate visitor behaviors in an opened ended question (see Appendix B). After the participant completed the survey, they were thanked for their time and did not receive compensation for their participation. The questions were chosen from pilot a study done with a previous animal behavior servicelearning class and with consultation with zoo staff. We were asked by the zoo staff to keep the survey brief so as not to interrupt the experience of the zoo visitors. 


\section{Data Analysis}

Given the nonparametric nature of the data and the non-normal distributions in the Likert scale measures, Spearman correlations were used to assess the associations between the study variables. Gender differences were tested using a Mann-Whitney U. Although not reported herein, parametric tests also confirmed the significant effects below. Finally, path analyses in structural equation modeling (using robust maximum likelihood estimation given the non-normal nature of the data) were also employed to test for potential indirect effects in the data.

\section{Results}

\section{Descriptive Results}

During our observations of zoo visitors, researchers observed 35 different cases of inappropriate or disruptive behavior such as hitting glass enclosures or otherwise trying to provoke the animals with noise (Figure 1a). When participants were asked in an open-ended question if they had personally seen inappropriate behavior in other zoo visitors and what those behaviors might be, 162 behaviors were reported. The most common behavior reported by visitors was also hitting the glass, provoking the animals, and various other disruptive or inappropriate behaviors (Figure 1b) similar to what we had observed.

\section{Figure 1}

Inappropriate Observed (a) and Reported (b) Behaviors in Zoo Visitors

a. Observed Behaviors

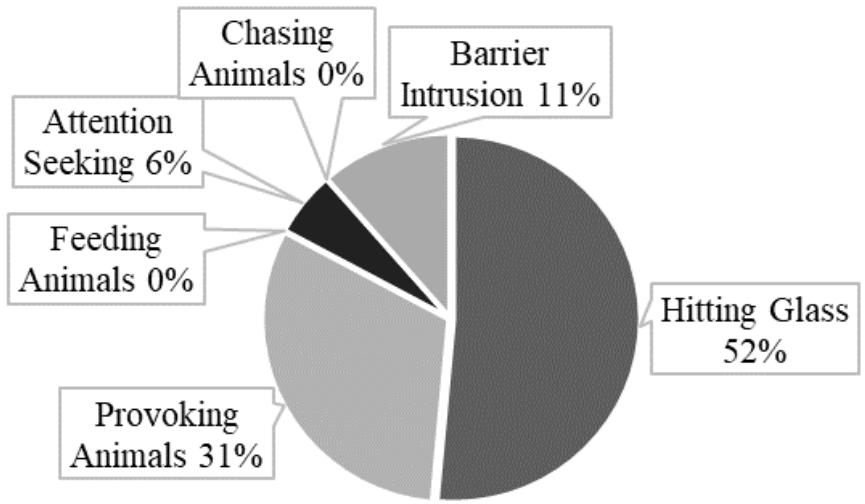

b. Reported Behaviors

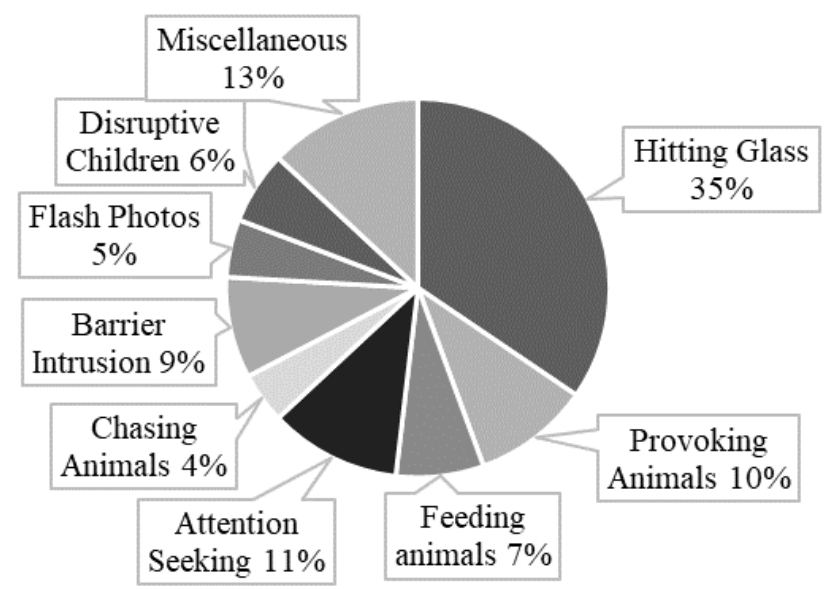

Note. During our naturalistic observation, we observed 35 cases of inappropriate or disruptive behaviors by zoo visitors (a). When participants were asked if they have personally seen other visitors displaying inappropriate behaviors (b), their reports closely matched our observations indicating that visitors at this zoo seem to know what behaviors exhibited by others might be viewed as disruptive behaviors to an animal.

In our survey, participants were also asked to indicate how important education, conservation, entertainment, and research were for a zoo. Participants identified the most important priority of a zoo was education and conservation and the least important priority was entertainment and research (see Table 2 for total numbers and Figure 2 for additional information). 
Table 2

Visitor Rankings of the Most Important Purpose of Zoos

\begin{tabular}{|c|c|c|c|c|c|}
\hline Purpose of Zoos Ranking & 1 & 2 & 3 & 4 & $\mathrm{n} / \mathrm{a}$ \\
\hline Education & $118(58.4)$ & $45(22.3)$ & $20(9.9)$ & $0(0.0)$ & $19(9.4)$ \\
\hline Conservation & $53(26.2)$ & $51(25.2)$ & $38(18.8)$ & $19(9.4)$ & $41(20.3)$ \\
\hline Entertainment & $44(21.8)$ & $22(10.9)$ & $20(9.9)$ & $88(43.6)$ & $28(13.9)$ \\
\hline Research & $13(6.4)$ & $33(16.3)$ & $70(34.7)$ & $42(20.8)$ & $44(21.8)$ \\
\hline
\end{tabular}

Note. Rank Order Table ( $n$ is included first, with \% in parenthesis). 1 indicates most important while 4 indicates least important, $\mathrm{n} / \mathrm{a}$ indicates not available or no rank given.

\section{Figure 2}

Rankings of Purpose of Zoos

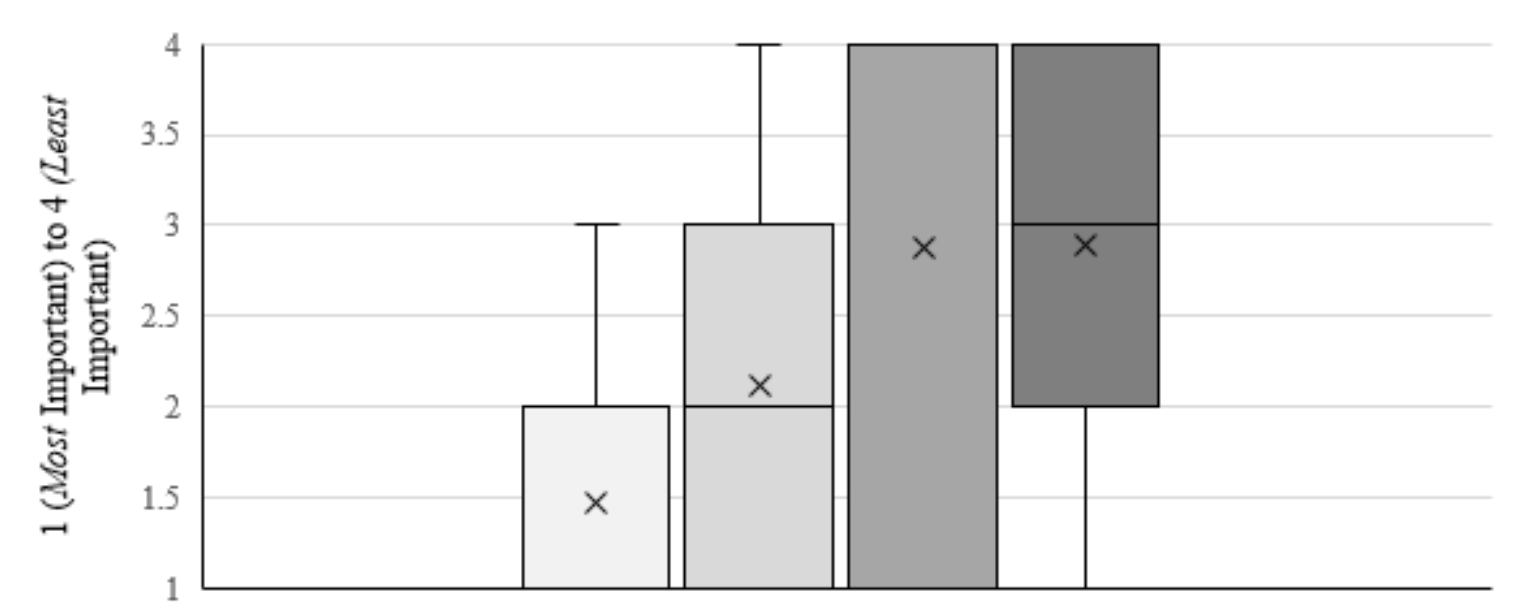

\section{Education $\square$ Conservation $\square$ Entertainment $\square$ Research}

Note. Box and whisker plot showing the highest, lowest, upper and lower quartile, and median rating of the purpose of the zoo. A rating of 1 on the scale indicates the most important while a rating of 4 indicates the least important purpose.

\section{Inferential Statistical Results}

Spearman correlations were conducted to determine if people's reported similarity between humans and animals and their reported empathy with animals were associated with the number of negative behaviors they reported seeing in other visitors. We found that the degree of similarity between humans and animals was positively associated with the number of reported inappropriate behaviors they saw in other visitors $\left(r_{s}(200)=.212, p(2\right.$-tailed $\left.)=.002\right)$. We also found that the degree to which visitors identified and empathized with animals at the zoo was also positively associated with the number of reported inappropriate behaviors they saw in other visitors $\left(r_{s}(200)=.221, p(2\right.$-tailed $\left.)=.002\right)$. Path analyses in structural equation modeling for indirect effects revealed that part of the association between the degree of similarity between humans and animals and the number of negative behaviors participants reported seeing in other visitors was explained by the degree with which they identify and empathize with animals at the zoo (indirect effect $=.075$, S.E. $=.037, z=2.047, p=.041$ ). In other words, the feeling that 
humans are more similar to animals was associated with reporting more negative behaviors partially due to its association with greater empathy for animals.

We then examined how a visitors' rating of the purpose of the zoo might be associated with these measures. Also using a Spearman correlation, we found the participants that ranked entertainment as the most important purpose of a zoo (1 on our Likert scale) reported less similarity between humans and animals $\left(r_{s}(200)=.255, p(2\right.$-tailed $\left.)=.001\right)$; and reported less inappropriate behaviors seen in other visitors $\left(r_{s}(200)=.200, p(2\right.$-tailed $\left.)=.009\right)$. In comparison, participants that ranked conservation as the most important purpose ( 1 on our Likert scale), reported seeing more inappropriate behaviors in other visitors $\left(r_{s}(200)=-.177, p(2\right.$-tailed $)=.029$, see Figure 3$)$.

\section{Figure 3}

Entertainment (a) and Conservation (b) Reported Purpose of Zoos and Visitor-Reported Inappropriate Behaviors in other Visitors

a. Entertainment

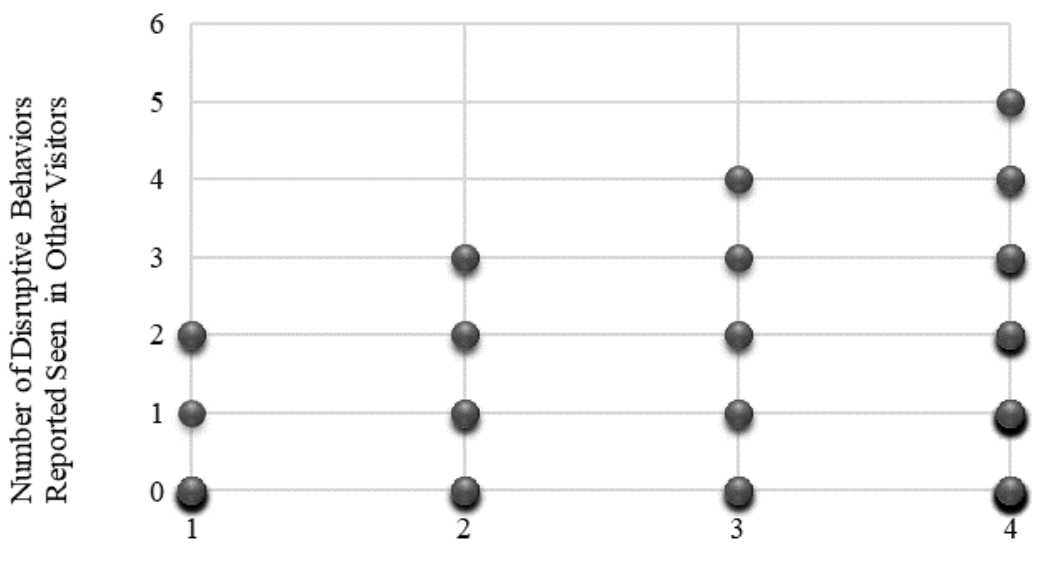

Purpose of Zoos (1= Most important), (4= Least important)

b. Conservation

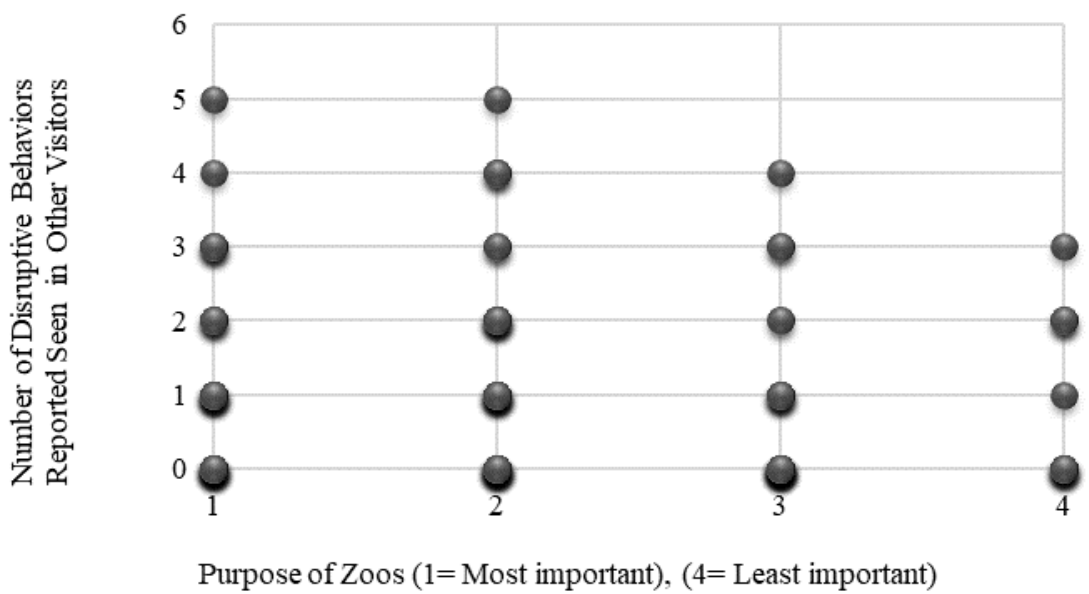

Note. Rating of the purpose of zoos and the number of reported disruptive behaviors in other zoo visitors. When entertainment was ranked the most important (rating of 1), fewer inappropriate behaviors were reported (a). When conservation was ranked as most important (rating of 1), more inappropriate behaviors were reported (b).

There was a significant association between gender and the level of empathy visitors had for zoo animals $(U=3359.50, p=.006)$, where women empathized more with zoo animals $(M=4.16, S D=$ 
0.90), compared to men $(M=3.68, S D=1.14)$. Additionally, there was a significant association between gender and the number of positive comments made about the zoo animals $(U=3140.50, p=.001)$, where women made more positive comments about the zoo animals $(M=1.38, S D=1.24)$, compared to men $(M$ $=0.87, S D=1.12$ ). No age differences were observed.

\section{Discussion}

In this study, we wanted to discreetly observe zoo visitor behaviors to determine if they engaged in inappropriate behaviors at the zoo and if the zoo visitors surveyed would report seeing similar inappropriate behavior in other visitors. Attention-seeking behaviors, such as hitting the glass enclosures or shouting, that we observed were also the behaviors people reported seeing the most in other zoo visitors. This suggests that many zoo visitors, especially those who empathize and identify highly with animals, are aware that some behaviors directed towards the zoo animals are disruptive and may cause distress. Previous research (Chiew, Butler, et al. 2019; Chiew, Hemsworth et al., 2019) has suggested that positive attitudes and context, such as enclosure barriers and signage, may influence the behavior of visitors as well as the behavior of animals in the exhibit. Our observed and participant reported behaviors aligned with previous work on zoo visitor effects (Davey, 2007; Sherwen \& Hemsworth, 2019); however, we did not observe differences between exhibit types.

One specific aim of this study was to determine whether visitor perceptions of the purpose of zoos and their perception of the similarity between humans and animals influences whether they report seeing inappropriate behavior in other visitors. People who reported seeing more inappropriate behaviors in other visitors had different perceptions of the similarity between humans and animals. The feeling that humans are similar to animals was tied to reporting more negative behaviors partially due to having more empathy/identity for animals. It should be noted that this survey question includes these two terms together for the breadth of respondents' comprehension, but future studies should examine these separately since empathy is the ability to understand the feelings of others while identifying with animals refers to a feeling of strong association or similarity to animals. Additionally, women in our study reported greater perceptions of empathy (and therefore identified more) with animals and made more positive comments about the animals when at the exhibits. This difference for empathy/identification is consistent with previous research that has also found gender differences in perceptions for animals, specifically empathy (Angantyr et al., 2011). Although we were not able to analyze how the visitors in the survey themselves behaved because our observations and the survey data was not always linked, this would be an important next step in the research. For example, it would be valuable to know how visitors' perception of a zoo, an enclosure, or a species observed influences their behavior while at the zoo. In other words, in addition to comments made in front of exhibits, do visitor perceptions influence their behavior in a way that would have either a positive, neutral, or negative impact on the welfare of the animals?

Perhaps the most interesting finding of this study was how participants ranked the purpose of the zoo and how that might influence their perception of animals and the behavior of other zoo visitors. As predicted, zoo visitors who ranked entertainment as a more important purpose of a zoo, reported less perceived similarity between humans and animals. They also were less likely to report negative behaviors observed in other zoo visitors. In contrast, people who ranked conservation as an important purpose of the zoo reported greater similarity between humans and animals and made more positive comments. As previous studies have shown, zoos often prioritize education and conservation (Carr \& Cohen, 2011; Roe et al., 2014); however, many visitors will report going to the zoo for entertainment purposes. Do the people that prioritize entertainment, also engage in attention-seeking behaviors that are potentially stressful or harmful towards the animals? Unfortunately, our data could not answer this question, but future research should examine this more closely. Understanding why people frequent the zoo, as well as their empathy and perception towards animals, might help zoos address these potential welfare concerns.

A few limitations of this study should be taken into consideration when interpreting the results. First, as Chiew, Hemsworth et al. (2019) reported, attitudes and perceptions are only half of the equation- 
context-dependent cues and exhibit construction can inform zoo visitor behavior. Context-dependent cues have been demonstrated to influence a range of behaviors, including increased litter on the ground with increased littering behavior from observational studies (Schultz et al., 2013). Thus, future research should investigate context further by testing whether signage that promotes the bio-behavioral similarities of a species may alter zoo visitor behavior at that exhibit.

Second, given that the survey questions were read aloud by the researcher, this may have influenced more respondents to indicate research and conservation as a higher priority than entertainment. Future research should address this issue to ascertain zoo visitors' perception of the primary purpose of the zoo especially since our findings differ from some previous studies (Carr \& Cohen 2011). Third, visitor responses might change depending on the animal(s) they were thinking of at the time of answering the survey even though the questions referred to animals in general. For example, visitors could have been thinking about the animals in the exhibits or other species. Because we were limited in this study on the number of questions we were permitted to ask zoo visitors, future studies should clarify this point to determine if the animal species and enclosure type influence how they view other visitors' behaviors in front of exhibits.

In conclusion, our findings suggest that zoo visitors' perception concerning the purpose of zoos and their perception of the similarity between humans and animals, which was explained by the degree with which they identify and empathize with animals at the zoo, influences what visitors report as inappropriate behavior around captive zoo animals. Future research should further explore if people's views on the purpose of zoos, specifically if they view them as a source of entertainment, influences their behavior towards captive animals. Likewise, programs designed to highlight the similarities between humans and animals might be another potential way to decrease inappropriate behaviors from zoo visitors.

Conflict of Interest Statement: We have no conflicts of interest to disclose.

\section{Acknowledgments}

We would like to thank Dr. Jonathan Santo for consultation regarding the statistical analysis of this paper and Jay Pratte, currently at the Utica NY Zoo, and all the zoo staff at the Omaha Henry Doorly Zoo for their input regarding this project. This work was supported through the University of Nebraska Omaha, Funds for Undergraduate Scholarly Experience (FUSE).

\section{References}

Altman, J. D. (1998). Animal activity and visitor learning at the zoo. Anthrozoös, 11(1), 12-21. https://doi.org/10.1080/08927936.1998.11425083

Andersen, L. L. (2003). Zoo education: From formal school programs to exhibit design and interpretation. International Zoo Yearbook,38(1), 75-81. https://doi.org/10.1111/j.17481090.2003.tb0206.x

Angantyr, M., Eklund, J., \& Hansen, E. M. (2011). A comparison of empathy for humans and empathy for animals. Anthrozoös, 24(4), 369-377. https://doi.org/10.2752/175303711x13159027359764

Aron, A., Aron, E. N., \& Smollan, D. (1992). Inclusion of other in the self-scale and the structure of interpersonal closeness. Journal of Personality and Social Psychology, 63(4), 596. https://doi.org/10.1037/00223514.63.4.596

Ballantyne, R., \& Packer, J. (2016). Visitors' perceptions of the conservation education role of zoos and aquariums: Implications for the provision of learning experiences. Visitor Studies, 19(2), 193-210. https://doi.org/10.1080/10645578.2016.1220185

Batt, S. (2009). Human attitudes towards animals in relation to species similarity to humans: A multivariate approach. Bioscience Horizons, 8(2), 180-190. https://doi.org/10.1093/biohorizons/hzp021 
Beatson, R. M., \& Halloran, M. J. (2007). Humans rule! The effects of creatureliness reminders, mortality salience and self-esteem on attitudes towards animals. British Journal of Social Psychology. 46(3), 619- 632. https://doi.org/10.1348/014466606x147753

Brando, S., \& Herrelko, E. S. (2021). Wild animals in the city: Considering and connecting with animals in zoos and aquariums. Bernice Bovenkerk, 341. https://doi.org/10.1007/978-3-030-63523-7_19

Brike, L. (2002). Effects of browse, human visitors and noise on the behaviour of captive orangutans. Animal Welfare, 11(2), 189-202.

Carr, N., \& Cohen, S. (2011). The public face of zoos: Images of entertainment, education and conservation. Anthrozoös, 24(2), 175-189. https://doi.org/10.2752/175303711x12998632257620

Chiew, S. J., Hemsworth, P. H., Sherwen, S. L., Melfi, V., \& Coleman, G. J. (2019). The effect of regulating zoo visitor-penguin interactions on zoo visitor attitudes. Frontiers in Psychology, 10, 2351. https://doi.org/10.3389/fpsyg.2019.02351

Chiew, S. J., Butler, K. L., Sherwen, S. L., Coleman, G. J., Fanson, K. V., \& Hemsworth, P. H. (2019). Effects of regulating visitor viewing proximity and the intensity of visitor behaviour on little penguin (Eudyptula minor) behaviour and welfare. Animals, 9(6), 285. https://doi.org/10.3390/ani9060285

Chiew, S. J., Hemsworth, P. H., Melfi, V., Sherwen, S. L., Burns, A., \& Coleman, G. J. (2021). Visitor attitudes toward little penguins (Eudyptula minor) at two Australian zoos. Frontiers in Psychology, $12,284$. https://doi.org/10.3389/fpsyg.2021.626185

Cole, J., \& Fraser, D. (2018). Zoo animal welfare: The human dimension. Journal of Applied Animal Welfare Science, 21(sup1), 49-58. https://doi.org/10.1080/10888705.2018.1513839

Davey, G. (2006). Relationships between exhibit naturalism, animal visibility and visitor interest in a Chinese Zoo. Applied Animal Behaviour Science, 96(1-2), 93-102. https://doi.org/10.1016/j.applanim.2005.04.018

Davey, G. (2007). Visitors' effects on the welfare of animals in the zoo: A review. Journal of Applied Animal Welfare Science, 10(2), 169-183. https://doi.org/10.1080/10888700701313595

Fernandez, E. J., Tamborski, M. A., Pickens, S. R., \& Timberlake, W. (2009). Animal-visitor interactions in the modern zoo: Conflicts and interventions. Applied Animal Behaviour Science, 120(1-2), 1-8. https://doi.org/10.1016/j.applanim.2009.06.002

Godinez, A. M., \& Fernandez, E. J. (2019). What is the zoo experience? How zoos impact a visitor's behaviors, perceptions, and conservation efforts. Frontiers in Psychology, 10, 1746. https://doi.org/10.3389/fpsyg.2019.01746

Hediger, H. (1969). Man and animal in the zoo. Routledge and Kegan Paul.

Hosey, G. (2013). Hediger revisited: How do zoo animals see us? Journal of Applied Animal Welfare Science, 16(4), 338-359. https://doi.org/10.1080/10888705.2013.827916

Hosey G., Melfi V., \& Ward S. J. (2020). Problematic animals in the zoo: The issue of charismatic megafauna. In F. Angelici \& L. Rossi (Eds), Problematic wildlife II (pp. 485-508). Springer. https://doi.org/10.1007/978-3$\underline{030-42335-3 \quad 15}$

Howell, T. J., McLeod, E. M., \& Coleman, G. J. (2019). When zoo visitors "connect" with a zoo animal, what does that mean? Zoo Biology, 38(6), 461-470. https://doi.org/10.1002/zoo.21509

Kratochvil, H., \& Schwammer, H. (1997). Reducing acoustic disturbance by aquarium visitors. Zoo Biology, 16(4), 349-353. https://doi.org/10.1002/(sici)1098-2361(1997)16:4<349::aid-zoo7>3.0.co;2-a

Lewis, R. N., Chang, Y. M., Ferguson, A., Lee, T., Clifforde, L., \& Abeyesinghe, S. M. (2020). The effect of visitors on the behavior of zoo-housed western lowland gorillas (Gorilla gorilla). Zoo Biology, 39(5), 283296. https://doi.org/10.1002/zoo.21552

Myers, O. E., Saunders, C. D., \& Birjulin, A. A. (2004). Emotional dimensions of watching zoo animals: An experience sampling study building on insights from psychology. Curator: The Museum Journal, 47(3), 299-321. https://doi.org/10.1111/j.2151-6952.2004.tb00127.x

Patrick, P. G., Matthews, C. E., Ayers, D. F., \& Tunnicliffe, S. D. (2007). Conservation and education: Prominent themes in zoo mission statements. The Journal of Environmental Education, 38(3), 53-60. https://doi.org/10.3200/joee.38.3.53-60

Pedersen, J., Sorensen, K., Lupo, B., \& Marx, L. (2019). Human-ape interactions in a zoo setting: Gorillas and orangutans modify their behavior depending upon human familiarity. Anthrozoös, 32(3), $319-332$. https://doi.org/10.1080/08927936.2019.1598651

Powell, D. M., \& Bullock, E. V. (2014). Evaluation of factors affecting emotional responses in zoo visitors and the impact of emotion on conservation mindedness. Anthrozoös, 27(3), 389-405. https://doi.org/10.2752/175303714x13903827488042 
Quadros, S., Goulart, V., Passos, L., Vecci, M., \& Young, R. (2014). Zoo visitor effect on mammal behaviour: Does noise matter? Applied Animal Behaviour Science, 156, 78-84. https://doi.org/10.1016/j.applanim.2014.04.002

Reade, L. S., \& Waran, N. K. (1996). The modern zoo: How do people perceive zoo animals? Applied Animal Behaviour Science, 47(1-2), 109-118. https://doi.org/10.1016/0168-1591(95)01014-9

Roe, K., McConney, A., \& Mansfield, C. F. (2014). The role of zoos in modern society-A comparison of zoos' reported priorities and what visitors believe they should be. Anthrozoös, 27(4), 529-541. https://doi.org/10.2752/089279314x14072268687808

Rose, P. E., Scales, J. S., \& Brereton, J. E. (2020). Why the "visitor effect" is complicated. Unraveling individual animal, visitor number, and climatic influences on behavior, space use and interactions with keepers-A case study on captive hornbills. Frontiers in Veterinary Science, 7, 236. https://doi.org/10.3389/fvets.2020.00236

Schultz, P. W., Bator, R. J., Large, L. B., Bruni, C. M., \& Tabanico, J. J. (2013). Littering in context: Personal and environmental predictors of littering behavior. Environment and Behavior, 45(1), 35-59. https://doi.org/10.1177/0013916511412179

Sherwen, S. L., \& Hemsworth, P. H. (2019). The visitor effect on zoo animals: Implications and opportunities for zoo animal welfare. Animals, 9(6), 366. https://doi.org/10.3390/ani9060366

Skibins, J. C., Powell, R. B., \& Hallo, J. C. (2013). Charisma and conservation: charismatic megafauna's influence on safari and zoo tourists' pro-conservation behaviors. Biodiversity and Conservation, 22(4), 959-982. https://doi.org/10.1007/s10531-013-0462-z

Skibins, J. C., Dunstan, E., \& Pahlow, K. (2017). Exploring the influence of charismatic characteristics on flagship outcomes in zoo visitors. Human Dimensions of Wildlife, 22(2), 157-171. https://doi.org/10.1080/10871209.2016.1276233

Taylor, N., \& Signal, T. D. (2005). Empathy and attitudes to animals. Anthrozoös, 18(1), 18-27. https://doi.org/10.2752/089279305785594342

Thompson, V. (1976). Observation of the great apes in a naturalistic zoo environment [Unpublished manuscript]. Lincoln Park Zoo.

Woods, B. (2002). Good zoo/bad zoo: Visitor experiences in captive settings. Anthrozoös, 15(4), 343-360. https://doi.org/10.2752/089279302786992478 


\section{Appendix A}

Visitor behavioral observation form used by researchers at the exhibits.

\begin{tabular}{|c|c|c|c|c|c|c|c|}
\hline \multicolumn{4}{|c|}{ Your Name } & ate & Start time: & Finish time: & Exhibit \\
\hline Sex & Age & $\mathrm{S} / \mathrm{W}$ & Noise Level & Observer & Positive Comments & Negative Comments & Notes \\
\hline \multirow{4}{*}{$\mathbf{M}$} & \multirow{4}{*}{$\begin{array}{c}19-30 \\
30+\end{array}$} & \multirow{4}{*}{$\begin{array}{l}\text { Stand } \\
\text { Walk }\end{array}$} & Exhibit: & \multirow{2}{*}{ Exhibit: } & & & \\
\hline & & & $\begin{array}{lll}1 & 2 & 3\end{array}$ & & & & \\
\hline & & & Person: & & & & \\
\hline & & & $\begin{array}{lll}1 & 2 & 3\end{array}$ & Animals: & & & \\
\hline \multirow{4}{*}{$\mathbf{M}$} & \multirow{4}{*}{$\begin{array}{c}19-30 \\
30+\end{array}$} & \multirow{4}{*}{$\begin{array}{l}\text { Stand } \\
\text { Walk }\end{array}$} & Exhibit: & \multirow{2}{*}{ Exhibit: } & & & \\
\hline & & & $\begin{array}{lll}1 & 2 & 3\end{array}$ & & & & \\
\hline & & & Person: & A. & & & \\
\hline & & & 12 & Animails: & & & \\
\hline \multirow{4}{*}{ M } & \multirow{4}{*}{$\begin{array}{c}19-30 \\
30+\end{array}$} & \multirow{4}{*}{$\begin{array}{l}\text { Stand } \\
\text { Walk }\end{array}$} & Exhibit: & \multirow{2}{*}{ Exhibit: } & & & \\
\hline & & & $\begin{array}{lll}1 & 2 & 3\end{array}$ & & & & \\
\hline & & & Person: & & & & \\
\hline & & & $\begin{array}{lll}1 & 2 & 3\end{array}$ & Animals: & & & \\
\hline \multirow{4}{*}{$\begin{array}{l}\text { M } \\
\text { F }\end{array}$} & \multirow{4}{*}{$\begin{array}{c}19-30 \\
30+\end{array}$} & \multirow{4}{*}{$\begin{array}{l}\text { Stand } \\
\text { Walk }\end{array}$} & Exhibit: & \multirow[b]{2}{*}{ Exhibit: } & & & \\
\hline & & & $\begin{array}{lll}1 & 2 & 3\end{array}$ & & & & \\
\hline & & & Person: & & & & \\
\hline & & & $\begin{array}{lll}1 & 2 & 3\end{array}$ & Animals: & & & \\
\hline \multirow{4}{*}{$\begin{array}{l}\text { M } \\
\text { F }\end{array}$} & \multirow{4}{*}{$\begin{array}{c}19-30 \\
30+\end{array}$} & \multirow{4}{*}{$\begin{array}{l}\text { Stand } \\
\text { Walk }\end{array}$} & Exhibit: & \multirow[b]{2}{*}{ Exhibit: } & & & \\
\hline & & & $\begin{array}{lll}1 & 2 & 3\end{array}$ & & & & \\
\hline & & & Person: & \multirow[b]{2}{*}{ Animals: } & & & \\
\hline & & & 12 & & & & \\
\hline
\end{tabular}




\section{Appendix B}

Script for approaching people

Hello, I'm from the University of Nebraska and I'm doing a zoo visitor survey. Would you mind answering 7 questions? It should only take 5 minutes.

Thank you for your time!

1) What do you consider the purpose of the zoo? (rank order with 1 as most important) Education

Conservation

Entertainment

Research

2) How do you view the relationship between humans and animals?

Separate,

nothing in common

1

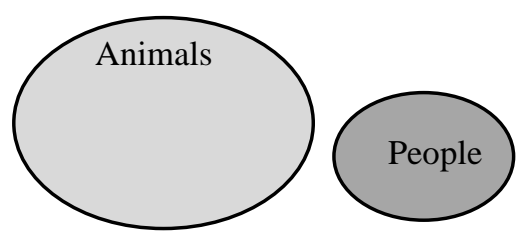

Close, several things in common

4

5

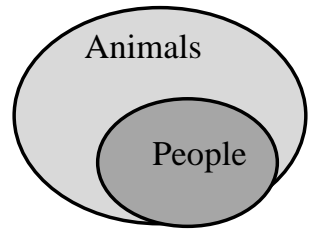

How much do you agree with the following statements?

\section{Disagree}

12

1

2

1

1

6) I attend as many zoo-keeper training sessions or demonstrations as possible.

7). Please describe the type(s) of inappropriate behavior you have seen at the zoo? Or, put an X here: , if you have never seen inappropriate behavior at the zoo. 